\title{
Young patient with hantavirus-induced myocarditis detected by comprehensive cardiac magnetic resonance assessment
}

Patrick Krumm ${ }^{1}$, Tanja Zitzelsberger ${ }^{1}$, Meinrad Gawaz ${ }^{2}$ and Simon Greulich ${ }^{2 *}$

\begin{abstract}
Background: We report a case of hantavirus-induced myocarditis in a young adult. Hantavirus showed a rapid increase of infections in the year 2017. Only scarce data is available about potential myocardial involvement in hantavirus infections. With ECG and echocardiography providing often inconclusive results, a multiparametric cardiac magnetic resonance protocol with distinct myocardial tissue characterization seems to be the adequate tool for detecting even slight myocardial alterations.

Case presentation: This case started with the presentation of young adult suffering from headache and abdominal pain. Thrombocytes were decreased, creatinine was elevated, and there was massive proteinuria. Puumala virus IgG ELISA turned out to be positive, and specific antibodies (IgG and $\operatorname{lgM}$ ) could be detected in the serum, and confirmed by immunoassay. The patient was admitted to the nephrology department for supportive therapy. Few days later, the patient reported chest pain and dyspnea. High sensitivity troponin I rose up to $0.32 \mu \mathrm{g} / \mathrm{l}$ (normal range below $0.04 \mu \mathrm{g} / \mathrm{l}$ ) with an increase of the creatinkinase to $319 \mathrm{U} / \mathrm{I}$ (normal max. $190 \mathrm{U} / \mathrm{l}$ ), no dynamic ECG changes could be observed. Echocardiography revealed a normal left ventricular function without regional wall motion abnormalities, no pericardial effusion or valve abnormalities, coronary artery disease could be excluded by computed tomography. A multiparametric cardiac magnetic resonance protocol including recent mapping techniques confirmed myocardial involvement induced by acute hantavirus infection. In the next few weeks, the patient's state of health rapidly improved and symptoms of chest pain and dyspnea disappeared. Follow up multiparametric CMR exam showed substantial decrease of the previously observed myocardial alterations during acute hantavirus infection suggesting myocardial healing.

Conclusions: This case demonstrates that a CMR protocol including recent mapping techniques and established late gadolinium enhancement technique is an adequate non-invasive tool for both 1) initial detection, and 2) follow up of patients with hantavirus-induced myocarditis, which might be more common than previously known.
\end{abstract}

Keywords: Hantavirus, Myocarditis, Cardiac magnetic resonance

\section{Background}

There was a substantial increase in hantavirus infections in 2017. Although primarily affecting the kidneys, this case draws attention to the fact that hantavirus might also involve the myocardium resulting in hantavirus-induced myocarditis which can be adequately 1 ) detected, and 2) followed by the use of a comprehensive cardiovascular magnetic resonance (CMR) assessment since CMR has

\footnotetext{
* Correspondence: simon.greulich@med.uni-tuebingen.de

²Department of Cardiology and Cardiovascular Diseases, University of

Tübingen, Otfried-Müller-Strasse 10, 72076 Tübingen, Germany

Full list of author information is available at the end of the article
}

proven high diagnostic value for detection of various myocardial pathologies, including patients with suspected myocarditis, cardiac sarcoidosis and other forms of non-ischemic cardiomyopathies $[1,2]$. To the best of our knowledge there are no clinical studies showing hantavirus infection causing myocardial disease.

\section{Case report}

A 36-year-old white male patient suffering from headache and abdominal pain presented at our emergency department. Initial ECG showed a sinus rhythm (40/min.) with a single $\mathrm{T}$-wave inversion in lead V2, and an

(c) The Author(s). 2019 Open Access This article is distributed under the terms of the Creative Commons Attribution 4.0 International License (http://creativecommons.org/licenses/by/4.0/), which permits unrestricted use, distribution, and 
incomplete right bundle branch block. Thrombocytes were decreased with $71.000 / \mu$ l (normal range 150.000$450.000 / \mu \mathrm{l})$, creatinine was elevated $(2.0 \mathrm{mg} / \mathrm{dl})$ with a maximum increase to $3.0 \mathrm{mg} / \mathrm{dl}$ (normal range $0.6-1.1$ $\mathrm{mg} / \mathrm{dl}$ ) and massive proteinuria. C-reactive protein was also elevated: $8.6 \mathrm{mg} / \mathrm{dl}$ (normal $<0.5 \mathrm{mg} / \mathrm{dl}$ ). Puumala virus IgG ELISA turned out to be positive, and specific antibodies (IgG and IgM) could be detected in the serum, and confirmed by immunoassay, also see Additional file 1 . The patient was admitted to the nephrology department for supportive therapy.

Six days later, the patient reported chest pain and dyspnea. High sensitivity troponin I rose up to $0.32 \mu \mathrm{g} / \mathrm{l}$ (normal range below $0.04 \mu \mathrm{g} / \mathrm{l}$ ) with an increase of the creatinkinase to $319 \mathrm{U} / \mathrm{l}$ (normal max. $190 \mathrm{U} / \mathrm{l})$, no dynamic ECG changes could be observed. The patient was admitted to the chest pain unit. Echocardiography revealed a normal left ventricular function (65\%) without regional wall motion abnormalities, no pericardial effusion or valve abnormalities. Since creatinine has normalized in the meantime, coronary artery disease was ruled out by coronary CT angiography.

CMR for work-up of suspected myocarditis was performed using a $1.5 \mathrm{~T}$ Magnetom Aera (Siemens Health Care, Germany). Cine-SSFPs revealed normal LV-EF (60\%) with no wall motion abnormalities. A modified LookLocker inversion recovery product sequence (MOLLI, MyoMaps) was used for $\mathrm{T}_{1}$-mapping and performed in a single mid-ventricular short-axis (SAX) slice at middiastole, prior and after application of contrast agent according to current recommendations [3]. $\mathrm{T}_{2}$-mapping was performed in the corresponding mid-ventricular SAX before administration of contrast agent using an ECGtriggered $\mathrm{T}_{2}$-prepared single-shot steady-state free precession (SSFP) product sequence with multiple $\mathrm{T}_{2}$ preparation times [4]. Normal values: native T1 $<1000$ ms, T2 < 50 ms. Analyses were made by cvi42 software (Circle, Canada).

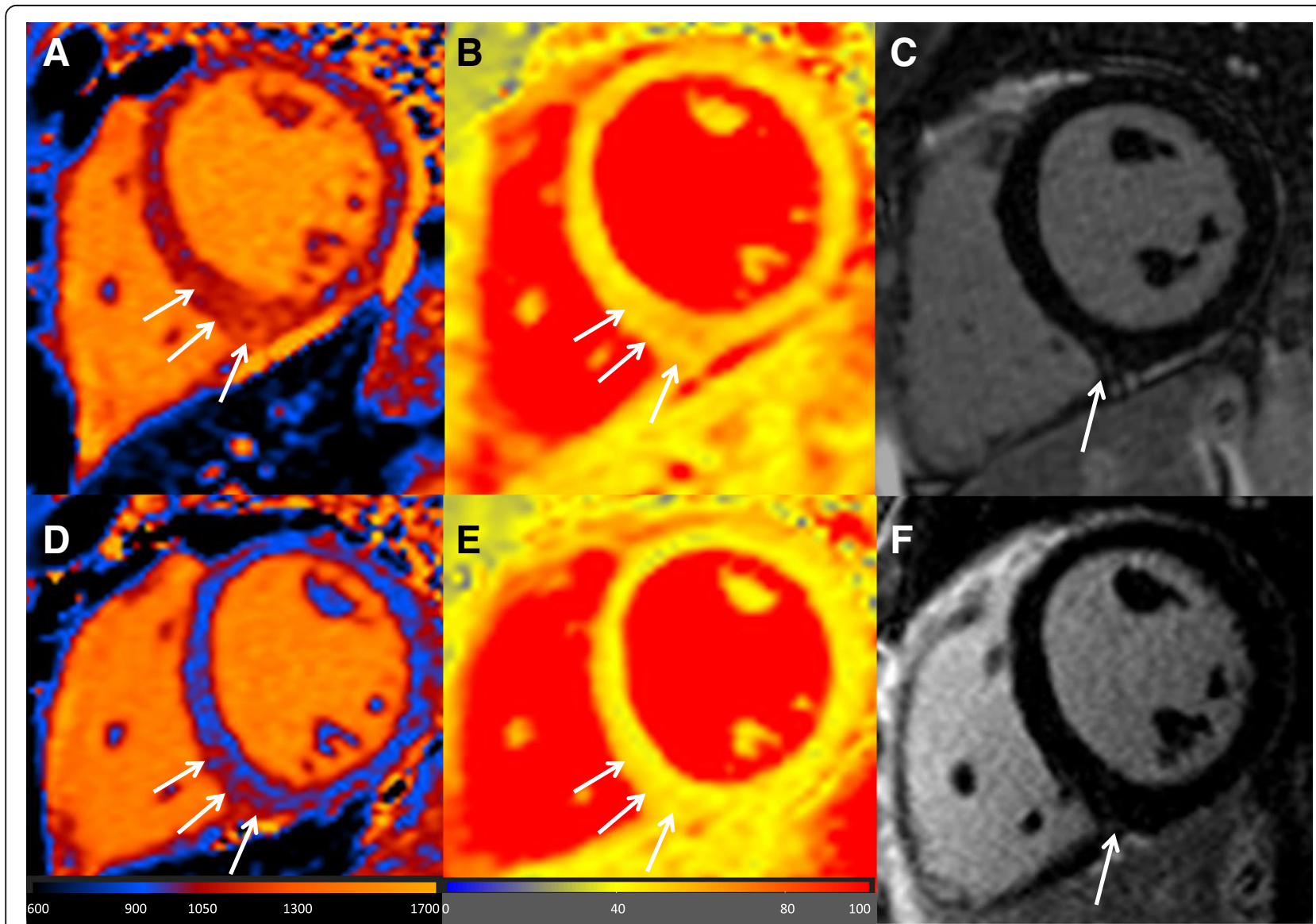

Fig. 1 Representative mid-ventricular short axis slice from the presented patient displaying native $T_{1}$-mapping technique (a), $T_{2}$-mapping technique (b), and late gadolinium enhancement (LGE) images (c). The upper row visualizes the baseline exam. In contrast to the mapping techniques (a \& $\mathbf{b})$, which show increased values with preponderance in the inferoseptal wall in comparison to normal values (native $\mathrm{T}_{1}: 1068 \pm 73 \mathrm{~ms}$ in the entire slice vs. $1122 \pm$ $31 \mathrm{~ms}$ in the inferoseptal wall; $T_{2}$ : entire slice $52 \pm 6 \mathrm{~ms}$, inferoseptal wall $55 \pm 6 \mathrm{~ms}$ ) no specific LGE could be detected in the inferoseptal wall (see arrows). In the bottom row, follow up images in the identical mid-ventricular short axis can be viewed. Note the signal decrease in the mapping images at follow up (d \& e) especially in the inferoseptal wall (arrows) suggesting a dynamic process (native $\mathrm{T}_{1}: 957 \pm 58 \mathrm{~ms}$ in the entire slice vs. $971 \pm 36 \mathrm{~ms}$ in the inferoseptal wall; $T_{2}$ : entire slice $44 \pm 5 \mathrm{~ms}$, inferoseptal wall $45 \pm 3 \mathrm{~ms}$ ), whereas the LGE image (f) turned out to be still negative 
Late gadolinium enhancement (LGE) images were acquired after contrast administration (Gadobutrol $0.15 \mathrm{mmol} / \mathrm{kg}$ ) using segmented inversion-recovery fast low angle shot (IR-FLASH).

Native $\mathrm{T}_{1}$-mapping demonstrated markedly elevated $\mathrm{T}_{1}$ values with preponderance in the inferoseptal wall $(1068 \pm 73 \mathrm{~ms}$ in the entire slice vs. $1122 \pm 31 \mathrm{~ms}$ in the inferoseptal wall), also see Figs. 1a and 2a. Furthermore, $\mathrm{T}_{2}$-mapping revealed increased values (entire slice $52 \pm$ $6 \mathrm{~ms}$, inferoseptal wall $55 \pm 6 \mathrm{~ms}$ ), suggesting myocardial edema representing active myocardial inflammation by hantavirus infection. In contrast, the LGE image, potentially indicating irreversible myocardial damage if positive, in the corresponding slice was negative (Fig. 1c). Despite negative LGE, this patient was considered having hantavirus-induced myocarditis due to: 1) clinical symptoms, 2) increased cardiac biomarkers, 3) exclusion of $\mathrm{CAD}$ and 4) conspicuous native $\mathrm{T}_{1}$ - and $\mathrm{T}_{2}$-mapping values detected by CMR.

In the next few weeks, the patient's state of health rapidly improved and symptoms of chest pain and dyspnea disappeared. Five months later, the patient was followed up by the same CMR protocol: Substantial decrease of native $\mathrm{T}_{1}$ values $(957 \pm 58 \mathrm{~ms}$ in the entire slice vs. $971 \pm 36 \mathrm{~ms}$ in the inferoseptal wall) and $T_{2}$ values (entire slice $44 \pm 5 \mathrm{~ms}$, inferoseptal wall $45 \pm 3 \mathrm{~ms}$ ) in the mid-ventricular slice position could be observed, again LGE-negative, suggesting myocardial healing (Fig. $1 \mathrm{~d}-\mathrm{f}$ ).

\section{Discussion and conclusions}

Hantavirus disease is one of the five most common notifiable viral diseases in Germany [5] with a rapid increase of

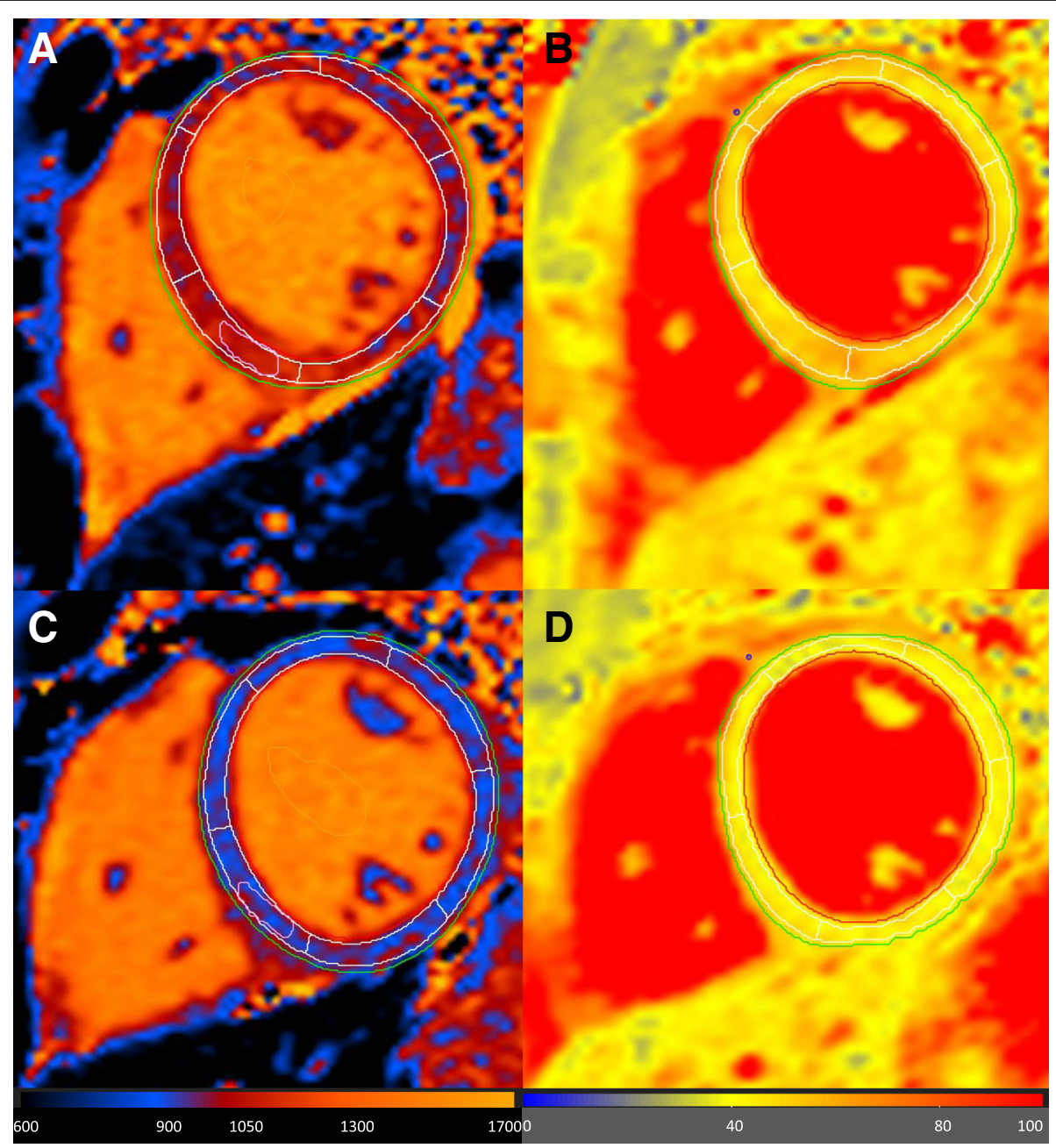

Fig. 2 Demonstrate the analysis in detail of the native $T_{1-}$ (a) and $T_{2}$-mapping (b) images from baseline (upper row) and native $T_{1-}$ (c) and $T_{2^{-}}$ mapping (d) images at follow up (bottom row). Since increased native $T_{1}$-mapping values can reflect both fibrosis and tissue edema, $T_{2}$-mapping can discriminate between both stages by detecting myocardial water content (=edema/inflammation). In this case, increased native $T_{1}$ and $T_{2}$ values at baseline exam indicated substantial inflammation (myocarditis), which decreased at follow up suggesting myocardial healing which is supported by the absence of LGE (indicating irreversible myocardial damage) both at baseline and follow up CMR 
infections in the year 2017 [6]. The viruses are RNA viruses of the Bunyaviridae family for which rodents are the natural reservoir. They can lead to haemorrhagic fever with renal syndrome in Asia and Europe, and hantavirus cardiopulmonary syndrome in America with reported case fatality rates of up to $35 \%$ [7].

Puumala virus is by far the most frequent cause of disease, which is characterized by acute kidney injury associated with thrombocytopenia and often proteinuria. Very few data is available about potential myocardial involvement [8,9]. Although discrete ECG changes may occur [9], cardiac function determined by echocardiography might be preserved. Therefore, an adequate non-invasive diagnostic tool is warranted. Since CMR provides excellent tissue characterization, this technique is able to delineate potential myocarditis, which is known to have severe impact on the patients' prognosis [10].

Myocardial inflammation leads to hyperemia with development of intracellular and interstitial edema, sometimes yielding irreversible myocyte damage, which can be visualized accurately by LGE. However, tissue edema without irreversible myocyte damage cannot be displayed by LGE. Furthermore, the value of LGE in displaying diffuse myocardial alterations is limited. Therefore, the sensitivity may be increased by combining LGE with recent $\mathrm{T}_{1}$ - and $\mathrm{T}_{2}$-mapping CMR techniques capable of detecting reversible or diffuse myocardial injury. Since increased native $T_{1}$ values might represent both fibrosis and edema/inflammation, $\mathrm{T}_{2}$-mapping by indicating myocardial water content (=edema/inflammation) is useful in discriminating between both stages. Therefore, it seems reasonable to combine LGE as well as $\mathrm{T}_{1}$-mapping and $\mathrm{T}_{2}$-mapping techniques performing a comprehensive CMR assessment $[1,2,11]$.

Although endomyocardial biopsy is the gold standard for diagnosis in suspected myocarditis it is invasive and might suffer from the sampling error. ECG and echocardiography are ubiquitous available and still the method of choice for initial evaluation of potential myocardial damage but these lack specificity. Thus, a comprehensive CMR approach consisting of 1) recent $T_{1}$ - and $T_{2}$-mapping techniques, which can detect also diffuse myocardial alterations by quantitative means in absolute values and can better separate between fibrosis and edema, and 2) established LGE, appear as the most reasonable non-invasive approach in patients with suspected myocarditis for both initial diagnosis and follow-up.

To the best of our knowledge, this is the first case demonstrating the benefit of a comprehensive CMR exam in a patient presenting with acute hantavirusinduced myocarditis. This case demonstrates that a CMR protocol including recent mapping techniques and established LGE is an adequate non-invasive tool for both 1) initial detection, and 2) follow up of patients with hantavirus-induced myocarditis, which might be more common than previously known.

\section{Additional file}

Additional file 1: Figure S1. The recomLine HantaPlus IgG, IgM line immunoassay from Mikrogen (Neuried, Germany) detects Puumala Virus (PuN), Sin Nombre Virus (SinN), Hantaan Virus (HaN), Dobrava Virus (DobN) and Seoul Virus (SeoN). The assay detects the serotype specific N-terminal part of the virus nucleocapsid antigen. This test provided strong evidence for infection with Puumala Virus (IgG and IgM strong positive) in our patient. (PPTX $297 \mathrm{~kb}$ )

\section{Abbreviations}

CAD: Coronary artery disease; CMR: Cardiac magnetic resonance;

CT: Computed tomography; ECG: Electrocardiogram; ELISA: Enzyme-linked immunosorbent assay; Ig: Immunoglobulin; IR-FLASH: Inversion-recovery fast low angle shot; LGE: Late gadolinium enhancement; MOLLI: Modified LookLocker inversion; SAX: Short axis; SSFP: Steady-state free precession

\section{Acknowledgements}

Not applicable.

Funding

None.

\section{Availability of data and materials}

The datasets used and/or analysed of the study are stored at the University of Tuebingen in a locked room of Dr. Greulich and are available from him on reasonable request.

\section{Authors' contributions}

PK, TZ and SG analyzed and interpreted the imaging data. MG was a major contributor in writing the manuscript. All authors read and approved the final manuscript.

Ethics approval and consent to participate Not applicable.

\section{Consent for publication}

Written informed consent was obtained from the patient for publication of this Case Report and any accompanying images. A copy of the written consent is available for review by the Editor of this journal.

\section{Competing interests}

The authors declare that they have no competing interests.

\section{Publisher's Note}

Springer Nature remains neutral with regard to jurisdictional claims in published maps and institutional affiliations.

\section{Author details}

${ }^{1}$ Department of Radiology, University of Tübingen, Tübingen, Germany. ${ }^{2}$ Department of Cardiology and Cardiovascular Diseases, University of Tübingen, Otfried-Müller-Strasse 10, 72076 Tübingen, Germany.

Received: 14 June 2018 Accepted: 26 December 2018 Published online: 06 January 2019

References

1. Greulich S, Ferreira VM, Dall'Armellina E, Mahrholdt H. Myocardial inflammation-are we there yet? Curr Cardiovasc Imaging Rep. 2015;8(3):6 Review.

2. Puntmann VO, Peker E, Chandrashekhar Y, Nagel E. T1 mapping in characterizing myocardial disease: a comprehensive review. Circ Res. 2016 Jul 8;119(2):277-99. 
3. Di Bella G, Moon JC, Messroghli DR, Kellman P, Piechnik SK, Robson MD, Ugander M. Society for Cardiovascular Magnetic Resonance Imaging, cardiovascular magnetic resonance working Group of the European Society of Cardiology,et al. myocardial T1 mapping and extracellular volume quantification: a Society for Cardiovascular Magnetic Resonance (SCMR) and CMR working Group of the European Society of cardiology consensus statement. J Cardiovasc Magn Reson. 2013;15:92.

4. Giri S, Chung YC, Merchant A, Mihai G, Rajagopalan S, Raman SV, et al. T2 quantification for improved detection of myocardial edema. J Cardiovasc Magn Reson. 2009;11:56.

5. Kruger DH, Ulrich RG, Hofmann J. Hantaviruses as zoonotic pathogensin Germany. Dtsch Arztebl Int. 2013;110:461-7.

6. Robert Koch Institut, epidemiologisches Bulletin, Aktuelle Statistik meldepflichtiger Infektionskrankheiten 44. Woche 2017; 23. November 2017/ Nr. 47, Seite 548

7. Latus J, Schwab M, Tacconelli E, Pieper FM, Wegener D, Rettenmaier B, Schwab A, Hoffmann L, Dippon J, Müller S, Fritz P, Zakim D, Segerer S, Kitterer D, Kimmel M, Gußmann K, Priwitzer M, Mezger B, Walter-Frank B, Corea A, Wiedenmann A, Brockmann S, Pöhlmann C, Alscher MD, Braun N. Acute kidney injury and tools for risk-stratification in 456 patients with hantavirus-induced nephropathia epidemica. Nephrol Dial Transplant. 2015 Feb;30(2):245-51.

8. Rasmuson J, Lindqvist $P$, Sörensen $K$, Hedström M, Blomberg A, Ahlm C. Cardiopulmonary involvement in Puumala hantavirus infection. BMC Infect Dis. 2013 Oct 28;13:501.

9. Kitterer D, Greulich S, Grün S, Segerer S, Mustonen J, Alscher MD, Braun N, Latus J. Electrocardiographic abnormalities and relative bradycardia in patients with hantavirus-induced nephropathia epidemica. Eur J Intern Med. 2016 Sep;33:67-73.

10. Schumm J, Greulich S, Wagner A, Grün S, Ong P, Bentz K, Klingel K, Kandolf R, Bruder O, Schneider S, Sechtem U, Mahrholdt H. Cardiovascular magnetic resonance risk stratification in patients with clinically suspected myocarditis. J Cardiovasc Magn Reson. 2014 Jan 26;16:14

11. Schumm J, Greulich S, Sechtem U, Mahrholdt H. T1 mapping as new diagnostic technique in a case of acute onset of biopsy-proven viral myocarditis. Clin Res Cardiol. 2014 May;103(5):405-8.

Ready to submit your research? Choose BMC and benefit from:

- fast, convenient online submission

- thorough peer review by experienced researchers in your field

- rapid publication on acceptance

- support for research data, including large and complex data types

- gold Open Access which fosters wider collaboration and increased citations

- maximum visibility for your research: over $100 \mathrm{M}$ website views per year

At $\mathrm{BMC}$, research is always in progress.

Learn more biomedcentral.com/submissions 